\title{
Relações de simetria na estrutura de Eu te amo, de Antonio Carlos Jobim e Chico Buarque de Holanda
}

Symmetry Relations in the Structure of Eu te amo, by Antonio Carlos Jobim and Chico Buarque de Holanda

Carlos de Lemos Almada ${ }^{1}$ carlosalmada@musica.ufrj.br 


\section{Resumo}

Este artigo propõe uma análise detalhada da estrutura de alturas da canção Eu te amo, de Antonio Carlos Jobim e Chico Buarque de Holanda, através de uma adaptação da metodologia schenkeriana com ferramentas originadas na chamada Teoria PósTonal. Busca-se evidenciar as complexas relações de simetria que caracterizam a peça, baseadas na interação das classes intervalares 1, 5 e 6 . Após uma avaliação analítica do texto da canção e de sua forma poética, o que estabelece uma base para o subsequente exame das correlações entre música e poesia, o artigo apresenta uma discussão sobre os problemas associados ao emprego da teoria schenkeriana nas músicas pós-tonal e popular, suportada pela literatura sobre o assunto (STRAUS , 1987; LERDAHL, 1989; FORTE, 1995; McGOWAN, 2008; LARSON, 1998; 2009, entre outros). A análise que se segue revela a extraordinária infraestrutura simétrica (que se projeta em diversos níveis de organização) sobre a qual é construída a canção, o que inclui interações com 0 argumento poético. Conclui-se que, embora não perfeitamente ajustada aos modelos da Ursatz schenkeriana, a estrutura complexa e estratificada de $E u$ te amo deriva de uma lógica particular, consistente em relação a exemplares de similar natureza da obra jobiniana.

Palavras-chave: Simetria intervalar. Jobim e Chico Buarque. Análise schenkeriana em música popular. Relação texto e música.

\section{Abstract}

This article proposes a detailed analysis of the pitch structure of the song Eu te amo, composed by Antonio Carlos Jobim and Chico Buarque de Holanda, through an adaptation of the Schenkerian methodology with tools originated in the so-called PostTonal Theory. It aims to highlight the complex relationships of symmetry that characterize the piece, which involve the interaction of the interval classes 1, 5 and 6. After an analytical evaluation of the lyrics and the poetic form, which establishes a basis for the subsequent examination of the correlations between music and text, the article presents a discussion of the problems associated with the use of Schenkerian theory in post-tonal and popular music, supported by the literature on these subjects (STRAUS, 1987; LERDAHL, 1989; FORTE, 1995; MCGOWAN, 2008; LARSON, 1998; 2009, among others). The analysis that follows reveals the extraordinary symmetrical infrastructure (projected at different levels of organization) on which the song is built, which includes interactions with the poetic argument. In conclusion, although not perfectly adjusted to the models of Ursatz schenkeriana, the complex and layered structure of the piece has its own logic, consistent in relation to examples of similar nature of the Jobinian work.

Keywords: Intervallic symmetry. Jobim and Chico Buarque. Schenkerian analysis in popular music. Relationship between text and music.

\footnotetext{
1 Flautista, compositor, arranjador e professor associado da Universidade Federal do Rio de Janeiro. Pesquisador interessado especialmente em variação musical e estudos sistemáticos em música popular, com diversas participações em congressos internacionais e dezenas de artigos publicados. Autor dos livros Arranjo (2001), A estrutura do choro (2006), Harmonia funcional(2009), Contraponto em música popular (2013) e Nas fronteiras da tonalidade (2016). Membro da Associação Brasileira de Teoria e Análise, líder do grupo de pesquisa MusMat e editor-chefe do periódico MusMat: Brazilian Journal of Music and Mathematics.
} 


\section{Introdução}

Composta em 1980 por Tom Jobim (música) e Chico Buarque (letra), a canção Eu te amo é considerada uma das mais líricas e pungentes dessa rica parceria. A peça foi encomendada para o longa-metragem homônimo de Arnaldo Jabor, estreado no ano seguinte, sendo protagonizado pelos atores Sônia Braga e Paulo César Peréio. O roteiro é baseado em um caso de amor intenso, porém turbulento e instável entre um casal recém-separado. A canção, que retrata de maneira ímpar as oscilações, incertezas e paixões profundas envolvidas, foi considerada pela crítica da época um dos principais atrativos do filme. ${ }^{2}$

Talvez a principal característica de Eu te amo, e que torna a obra tão atraente ao público (mesmo fora de seu original contexto cinematográfico), seja a integração entre letra e música. O caráter do argumento poético consiste em um sofrido lamento, enunciado em primeira pessoa pelo protagonista (que se depreende pelo texto ser do sexo masculino) e dirigido à amante que acaba de deixá-lo. ${ }^{3} \mathrm{O}$ texto alterna passado e presente, respectivamente representados por lembranças felizes do casal e a dura realidade da ruptura. Tal alternância é claramente percebida nos versos, que podem ser classificados em três grupos, de acordo com os estados mentais sugeridos: reminiscências em formato de flashbacks (por exemplo, "Se, ao te conhecer, dei pra sonhar, fiz tantos desvarios"), perplexidade, especialmente denotados por perguntas retóricas, como "Me conta agora como hei de partir", e amargura ("Não, acho que estás te fazendo de tonta"). Em relação a tal conteúdo poético, as três primeiras estrofes (A, B e C) apresentam a mesma organização: dois versos do primeiro grupo (lembranças doces), fechando com um do segundo. ${ }^{4}$ A quarta estrofe (D) traz uma estrutura distinta, como se 0 protagonista se desse conta finalmente de sua situação, o que se denota pelo tom queixoso de seu primeiro verso ("Se entornaste a nossa sorte pelo chão"). Sintomaticamente, esse é o único bloco que parece ser inteiramente ambientado no "presente". ${ }^{5}$ Tal ponto parece indicar uma mudança psíquica da personagem: os estados mentais passam a não ser mais claramente definidos (como se o presente "contaminasse" o passado) e a expressão pessoal, mesmo nas lembranças, se torna mais amarga. A partir dessas considerações preliminares, o Quadro 1 propõe uma organização formal para o texto, distribuindo seus 21 versos pelas sete estrofes.

Na realização musical do texto por Jobim (correspondendo essencialmente às construções melódica e harmônica), algumas estrofes mantêm relações de correspondência,

2 Eu te amo foi primeiramente gravada por Chico Buarque, em dueto com Telma Costa, em seu álbum “Vida", lançado em 1980 pelo selo Philips.

3 Um aspecto relevante do tratamento musical dado a esse argumento é o constante contorno descendente, especialmente cromático (considerando vários níveis de organização, como será visto) que descrevem melodia, harmonia (referindo-se aqui à condução das vozes acordais) e linha de baixo. Pelos princípios da retórica musical e da Teoria dos Afetos, tal tipo de perfil melódico é associado à ideia de profunda dor e lamentação, uma associação cultural até hoje fortemente presente, em especial na música para cinema.

4 Interessantemente, a dualidade passado/presente sugere uma atmosfera quase cinematográfica para a canção.

5 Entretanto, na retomada musical dessa estrofe (em F), a estrutura poética não parece corroborar essa interpretação, com um caráter mais próximo ao das estrofes iniciais (i.e., passado-presente). 
como sugere o esquema gráfico da Fig. 1. Setas cheias indicam o fluxo musical. ${ }^{6}$ Retângulos representam as sete estrofes, sendo que aqueles alinhados verticalmente evidenciam replicação de conteúdo melódico-harmônico. É o caso das estrofes $E$ e G (que reproduzem o conteúdo de $\mathrm{C}$ ) e da estrofe $\mathrm{F}$ (idêntica a $\mathrm{D}$ ). A seta em traço-ponto denota que as estrofes A e C mantêm entre si uma relação um pouco mais complexa, aqui denominada de relação tritônica (o que terá importantes desdobramentos ao longo do estudo).

Quadro 1: Estrutura formal do texto de Eu te amo.

\begin{tabular}{|c|c|c|}
\hline estrofes & versos & Texto \\
\hline \multirow{3}{*}{ A } & 1 & Ah, se já perdemos a noção da hora \\
\hline & 2 & Se juntos já jogamos tudo fora \\
\hline & 3 & Me conta agora como hei de partir \\
\hline \multirow{3}{*}{ B } & 1 & $\begin{array}{l}\text { Se, ao te conhecer, dei pra sonhar, fiz tantos } \\
\text { desvarios }\end{array}$ \\
\hline & 2 & Rompi com o mundo, queimei meus navios \\
\hline & 3 & Me diz pra onde é que ainda posso ir \\
\hline \multirow{3}{*}{ C } & 1 & Se nós, nas travessuras das noites eternas \\
\hline & 2 & Já confundimos tanto as nossas pernas \\
\hline & 3 & Diz com que pernas eu devo seguir \\
\hline \multirow{3}{*}{$\mathrm{D}$} & 1 & Se entornaste a nossa sorte pelo chão \\
\hline & 2 & Se na bagunça do teu coração \\
\hline & 3 & Meu sangue errou de veia e se perdeu \\
\hline \multirow{3}{*}{$\mathrm{E}$} & 1 & Como, se na desordem do armário embutido \\
\hline & 2 & Meu paletó enlaça o teu vestido \\
\hline & 3 & E o meu sapato inda pisa no teu \\
\hline \multirow{3}{*}{$\mathrm{F}$} & 1 & Como, se nos amamos feito dois pagãos \\
\hline & 2 & Teus seios inda estão nas minhas mãos \\
\hline & 3 & Me explica com que cara eu vou sair \\
\hline \multirow{3}{*}{ G } & 1 & Não, acho que estás te fazendo de tonta \\
\hline & 2 & Te dei meus olhos pra tomares conta \\
\hline & 3 & Agora conta como hei de partir \\
\hline
\end{tabular}

6 Aqui é considerada apenas a forma referente ao desenrolar poético básico, desconsiderando tanto o interlúdio instrumental quanto as subsequentes repetições da letra. 


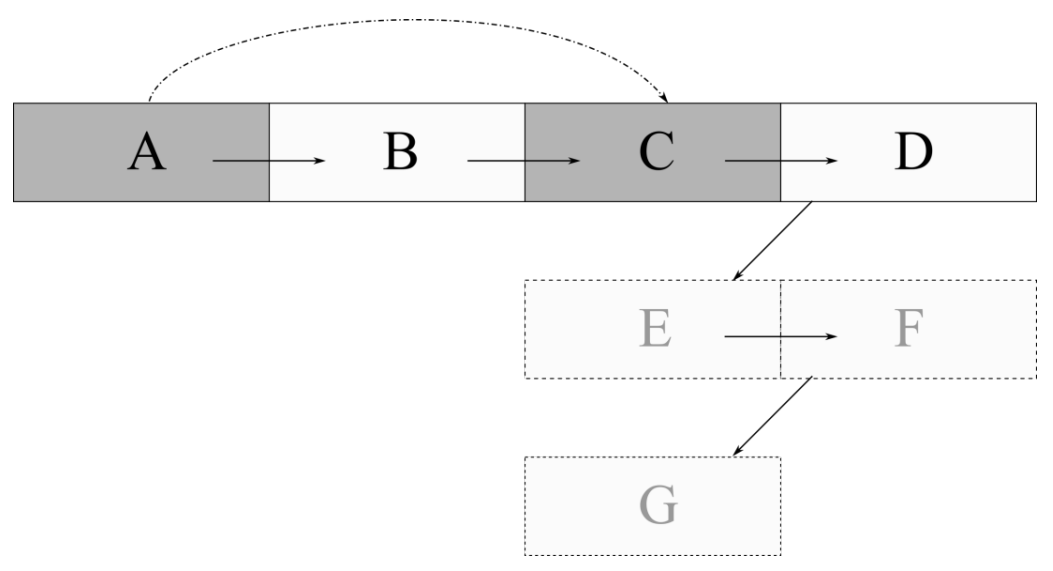

Fig. 1: Representação da disposição das estrofes na canção. Células verticalmente alinhadas indicam mesmo conteúdo melódico-harmônico. As células sombreadas (e a seta curva) indicam equivalência por relação tritônica.

Este artigo propõe um exame analítico detalhado do conteúdo musical dessas quatro estrofes distintas (A, B, C e D), com o intuito de evidenciar a rede estratificada de inter-relações que envolvem as estruturas melódica, harmônica (incluindo condução das vozes acordais e linha de baixo) e, menos intensamente, a dimensão textual, e que tornam Eu te amo uma obra de grande originalidade e rara complexidade no âmbito da música popular.

A partir desse objetivo, a análise schenkeriana (devidamente adaptada às condições do objeto de estudo) mostra-se como o método mais adequado de abordagem. Em complemento, visando o aumento da acurácia e da eficiência analítica, o processo de análise incorpora ainda formulações e ferramentas derivadas da assim chamada Teoria Pós-tonal, em especial representações geométricas de relações de alturas.

\section{Análise schenkeriana em música popular}

Antes de propriamente iniciar a análise de Eu te amo, parece necessário e oportuno discutir algumas questões envolvidas na aplicação do método schenkeriano em música popular.

Felix Salzer (1904-1986), discípulo de Heinrich Schenker (1868-1935), emigrou para os Estados Unidos com o início da Segunda Grande Guerra tornando-se não apenas um dos principais responsáveis pela difusão e popularização da teoria de seu mestre no meio acadêmico norte-americano, mas também o primeiro entre muitos teóricos posteriores a propor flexibilizações de suas rígidas bases originais. Nesse sentido, seu influente livro Structural Hearing (publicado em 1952) apresenta duas propostas inovadoras. Uma delas corresponde à expansão do repertório primordialmente almejado por Schenker, ${ }^{7}$ com a inclusão de obras de compositores pré- (como Josquin, por exemplo) e pós-tonais (Hindemith, Bartók e Stravinsky, entre outros). A segunda, de certo modo uma consequência da primeira, consiste na incorporação à análise de novas convenções, técnicas e elementos gráficos, inaugurando

7 A saber, abrangendo a chamada Era da Prática Comum, e mais especificamente, a tradição austro-germânica entre J. S. Bach e Brahms. 
uma tendência que se propagaria até os dias atuais e, provavelmente, é o fator que melhor explica a popularidade do método num amplo espectro de abordagens teórico-analíticas. Tal tendência pode ser talvez sucintamente descrita como uma combinação de abstrações e generalizações de preceitos essenciais (especialmente o emprego de reduções para evidenciar elementos estruturais e a ideia de camadas hierarquizadas) e a inclusão de procedimentos e elementos idiossincráticos, enquanto outros são relativizados, diluídos ou mesmo desconsiderados.

Tal quadro fez multiplicar o número de abordagens schenkerianas não estritas, ou seja, que adotam de maneira livre e particular os princípios originais, comumente filtrados por características e demandas do objeto de estudo. Enquanto essa expansão pode ser vista como um saudável processo de enriquecimento e exploração de novas alternativas, levando a teoria a latitudes inéditas e não imagináveis pelo próprio Schenker, ela de modo algum é imune a questionamentos.

Um aspecto atual e potencialmente polêmico que advém de tais circunstâncias, por exemplo, envolve o emprego da análise schenkeriana em música não tonal, um tema que tem seu ponto de partida em um bem conhecido artigo de Robert Morgan, publicado em 1976, que introduz a ideia de prolongamento dissonante (dissonant prolongation). Em 1987, Joseph Straus traz especificamente o assunto para o âmbito da atonalidade, a partir do exame sistemático de quatro condições que considera necessárias para a existência de prolongamento. ${ }^{8} \mathrm{~A}$ partir dessas premissas e após o exame analítico de uma série excertos de obras de Schoenberg, Stravinsky, Bartók, Webern, entre outros, Straus advoga a ideia de que as relações de coerência estrutural na música não tonal seriam mais associativas do que propriamente prolongacionais. Tal discussão seria dois anos depois enriquecida por um estudo de Fred Lerdahl (1989). O autor inicia o artigo comentando os principais problemas inerentes à aplicação do método schenkeriano no exame da música pós-tonal (alguns deles semelhantes às condições de Straus) como, por exemplo, questões referentes à segmentação do discurso musical, relações de inclusão entre conjuntos e a ausência de uma clara hierarquia de eventos de altura. Em suas palavras, "adaptações schenkerianas para a música atonal se provaram como controversas tanto para crentes quanto não crentes da fé schenkeriana" (LERDAHL, 1989, p. 67, tradução do presente autor). ${ }^{9}$ A despeito disso, Lerdahl é menos categórico que Straus em suas conclusões, considerando que seria possível o desenvolvimento de

[...] uma teoria prolongacional atonal [capaz de] explicar as importantes intuições de elaboração e conexão linear que a música atonal evoca, [bem como] relacionar o prolongamento atonal ao tonal em um nível mais abstrato do que Straus considera, fornecendo assim uma base teórica comum entre os dois idiomas (LERDAHL, 1989, p. 68, tradução do presente autor). ${ }^{10}$

8 São elas: (1) Condição de consonância-dissonância (consonance-dissonance condition); (2) Condição de grau escalar (scale-degree condition); (3) Condição de embelezamento (embellishment condition); e (4) Condição de harmonia/condução de vozes (harmony/voice-leading condition). Para maiores detalhes, ver STRAUS (1987, p.2-5).

9 Original: "Schenkerian adaptations to atonal music have proved controversial to both believers and nonbelievers in the Schenkerian faith." (LERDAHL, 1989, p. 67)

10 Original: "[...] an atonal prolongational theory [that] can account for the important intuitions of elaboration and linear connection that atonal 
Lerdahl propõe um novo modelo como uma ramificação de sua então recentemente publicada Teoria Gerativa da Música Tonal (LERDAHL; JACKENDOFF, 1983). Buscando um sistema equivalente ao conjunto de regras de boa formação e de preferência, que embasa a análise de músicas tonais de um ouvinte aculturado, Lerdahl estabelece para os contextos atonais dez condições de saliência (salience conditions) ${ }^{11}$ que são, contudo, capazes de evidenciar apenas eventos com implicações locais, devido à ausência de relevo hierárquico do espaço de alturas atonal (flat space). Em contraste, o espaço tonal, estratificado por definição, permite que eventos possam exercer influências tanto local quanto globalmente, abrangendo muitas vezes largos períodos em uma obra. Segundo Lerdahl, sob a perspectiva global, eventos em música atonal passam depender mais intensamente de relações abstratas, especialmente o paralelismo motívico. ${ }^{12} \mathrm{~A}$ despeito da limitada capacidade de projeção desse espaço (se comparado ao espaço tonal), e da maior dependência em relação a configurações contextuais, Lerdahl demonstra em suas três análises (todas de trechos de peças de Schoenberg), com ajuda de suas condições de saliência (e considerando mesmo relações abstratas que emanam de conjuntos de classes de alturas), a viabilidade de distinguir de modo sistemático elementos estruturais de subsidiários na música pós-tonal. Entretanto, certamente em vista da problemática que lhe é inerente, o campo ainda hoje é relativamente pouco explorado, seja através de estudos teóricos ou analíticos.

Por outro lado, o emprego da teoria schenkeriana em análise de música popular tem se disseminado intensamente nos últimos anos. ${ }^{13}$ Ainda que haja profundas diferenças entre os diversos idiomas e gêneros que integram o vasto conjunto da música popular e, especialmente entre este e o universo atonal, alguns interessantes pontos de contato no que tange à aplicação do método schenkeriano podem ser elencados. Uma das questões mais distintivas é justamente a relativização do poder da tríade perfeita como fonte de significado estrutural para uma obra. Em certos gêneros musicais, como o jazz ou a bossa nova, componentes acordais considerados como dissonantes (sextas, sétimas, nonas etc.) em obras do período da prática comum são perfeitamente aceitáveis como elementos estáveis, o que permite, ao menos em potencial, que tenham suas sonoridades prolongadas. ${ }^{14}$ Além disso, sintaxes harmônicas com lógicas distintas da funcionalidade tonal S-D-T (como acontece no blues, no rock ou no chamado jazz modal) fazem surgir modelos de prolongamento que desafiam os esquemas tradicionais de Ursatz.

É também característico de aplicações schenkerianas em música popular o uso parcial e seletivo de elementos do método, uma prática cada vez mais frequente. Um dos trabalhos pioneiros nesse sentido foi realizado por Allen Forte (1995), que empregou técnicas adaptadas

\footnotetext{
music evokes [as well as] relate atonal to tonal prolongation at a more abstract level than Straus considers, thereby providing common theoretical ground between the two idioms." (LERDAHL, 1989, p. 68)

11 Referentes à proeminência de eventos em relação a timbre, dinâmica, duração, posição métrica etc. Lerdahl também assinala pesos (de um a três) às suas condições, de acordo com o impacto prolongacional que podem causar.

12 De acordo com o autor (LERDAHL, 1989, p. 85), "motivo, harmonia e espaço de alturas tendem a se mesclar" ("Motive, harmony, and pitch space tend to merge into one another").

13 Para uma interessante discussão sobre a propriedade do emprego de análise schenkeriana no repertório popular, ver Gallardo (2000).

14 O que faz com que a discussão proposta por Robert Morgan (1976), originalmente voltada para música de concerto mais dissonante, seja também oportuna neste contexto.
} 
da teoria de Schenker para analisar a estrutura de baladas da chamada era de ouro (golden age) da canção norte-americana. A maneira flexível e livre que Forte se utilizou do método (o que incluiu a elaboração de novas convenções gráficas), buscando pragmaticamente evidenciar elementos estruturais em foco, certamente influenciou vários outros trabalhos com objetivos locais semelhantes. ${ }^{15}$

O jazz é outra vertente bem rica em relação a abordagens schenkerianas, uma tendência provavelmente iniciada por um importante artigo de Steven Gilbert, ${ }^{16}$ publicado em 1984, voltado para o exame da música de um compositor atuante na fronteira entre o jazz e a música de concerto, George Gershwin.

Uma questão sempre presente nesses estudos é o papel da dissonância estável (stable dissonance), adotando aqui o bem apropriado termo proposto por Forte (1995, p.51) para se referir a sextas, sétimas e tensões harmônicas ${ }^{17}$ adicionadas a tríades como enriquecimento sonoro. Em um artigo sobre a dualidade consonância/dissonância no idioma jazzístico, James McGowan (2008, p. 95) comenta justamente esse conceito de Forte, afirmando que "tal associação [ou seja, por parte de Forte] do termo 'estável' com 'dissonante' é bastante peculiar, uma vez que os termos são, no sentido schenkerianos, polos opostos". ${ }^{18} \mathrm{Na}$ verdade, isso denota uma peculiaridade do contexto melódico-harmônico de certos gêneros populares que parece ser inconciliável com os preceitos mais básicos propostos por Schenker, um aspecto que tem despertado inquietação por parte de muitos teóricos.

Diante de tal dilema, três possíveis caminhos se apresentam, caminhos cujos princípios poderiam ser enunciados como se segue: (a) a análise schenkeriana é inaplicável ao exame de música com tais características (proposta "conformista" ou mais ortodoxa); (b) é aplicável, porém é preciso relativizar a importância das extensões acordais, buscando eliminá-las em reduções intermediárias, ${ }^{19}$ de modo a alcançar em níveis profundos estruturas normativas (proposta "adaptativa"); (c) a música popular tem sua própria lógica estrutural (em termos harmônicos, melódicos e da condução de vozes), merecendo, portanto, uma abordagem schenkeriana particular. Nesse sentido, eventualmente tensões não podem ser reduzidas de modo sistemático, e devem ser consideradas como possuindo mesmo status em relação a componentes da tríade (proposta "dissidente"). Do mesmo modo, a ideia da conformação aos tipos tradicionais de estruturas primordiais perde força e alternativas idiossincráticas tendem a tomar seus postos.

15 Ver, por exemplo, considerando os universos do rock e da música pop, Everett (1998; 2001), Lovell (2012) e Nobile (2015).

16 Gilbert e Forte são coautores de um influente livro sobre a teoria schenkeriana (tradicional), publicado em 1982.

17 Termo de comum uso no contexto da música popular, tensões (ou extensões) harmônicas se referem a notas-funções mais remotas em relação à estrutura básica de um acorde. São consideradas tensões as nonas, décimas primeiras e décimas terceiras.

18 Original: "His association of the term 'stable' with 'dissonant' is quite peculiar since the terms are, in some Schenkerian senses, polar opposites." (McGOWAN, 2008, p. 95).

19 Tal argumentação é sustentada por autores como Steve Larson, que considera que, a despeito da maior liberdade com que as dissonâncias são tratadas (especialmente no jazz moderno), "seus significados básicos permanecem o mesmo: uma dissonância deriva seu significado de alturas mais estáveis [posicionadas] em níveis mais profundos da estrutura" (Original: "their basic meaning remains the same: a dissonance derives its meaning from more stable pitches at deeper structural levels") (LARSON, 1998, p. 213). 0 autor mantém e aprofunda essa discussão em um livro voltado especialmente para o exame schenkeriano de improvisação jazzística, com análises de improvisos de três pianistas consagrados: Bill Evans, Thelonious Monk e Oscar Peterson (LARSON, 2009). 
Como ficará claro ao longo deste artigo, a terceira proposta é a que parece ser a mais adequada para o exame da estrutura de Eu te amo. Na verdade, algumas das canções de Jobim que possuem estruturas de raras originalidade e complexidade no âmbito da música popular, são especialmente refratárias a análises schenkerianas "tradicionais". É o caso, por exemplo, de Chovendo na roseira e Samba de uma nota só, ambas analisadas com metodologia, por assim dizer, neo-schenkeriana por Carlos Almada em dois artigos (2010; 2012). Tais análises revelam não apenas tensões melódicas que exercem papéis centrais, irredutíveis (especialmente no Samba), como Ursätze que não se enquadram aos modelos convencionais. As conclusões obtidas em ambos os trabalhos formam um sólido suporte para o presente estudo que, no entanto, traz também novas perspectivas para a concepção estrutural jobiniana, como é apresentado na próxima seção.

\section{Análise estrutural de Eu te amo}

Algo que é geralmente trivial - a determinação da tonalidade de uma peça a ser analisada - torna-se em Eu te amo uma tarefa que requer algumas considerações. De início, há uma série de ambiguidades essenciais à própria canção que não deixam tão clara a questão (aspecto que está no cerne do próprio estudo e que será devidamente evidenciado e explorado ao longo da análise). Provavelmente devido a essa característica, editores de versões da partitura têm hesitado diante da decisão sobre tonalidade e armadura de clave. As três edições consultadas revelam alternativas distintas. Na mais antiga delas, presente no volume 1 do songbook produzido por Almir Chediak (JOBIM, 1995), a canção é escrita em formato de lead sheet (ou seja, melodia com indicações de harmonia em cifragem alfanumérica) na tonalidade de Dó maior (com a armadura de clave correspondente), o que se deve provavelmente à intenção de facilitar sua leitura. No Cancioneiro Jobim (2006), em edição patrocinada pelo Instituto Antonio Carlos Jobim, Eu te amo é notada como partitura de canto e piano em Ré-bemol maior, porém com armadura sem acidentes. Dois anos depois, uma versão quase idêntica seria publicada no Cancioneiro Chico Buarque (também sob os auspícios do Instituto e da editora Jobim Music), desta vez apresentando a armadura de clave de Ré-bemol maior. Uma pesquisa nos manuscritos da canção ${ }^{20}$ confirma esta última alternativa como a mais fidedigna às intenções originais, que será, portanto, aqui adotada como referencial. ${ }^{21}$

20 Que fazem do acervo pertencente ao Instituto Jobim. 0 acesso a esse material específico pode ser feito no seguinte link: http://www.jobim. org/jobim/handle/2010/3936.

21 Mais precisamente, a solução para a questão é intermediária: a partitura disponível pelo Instituto (http://www.jobim.org/jobim/bitstream/ handle/2010/4806/eu\%20te\%20amo.pdf?sequence=2) será a versão considerada neste estudo, porém com a armadura "correta" (ou seja, Ré-bemol maior), com as devidas adaptações enarmônicas, quando necessário. 


\subsection{Introdução}

A Fig. 2 inicia a análise com a introdução da canção. Três níveis de redução são considerados (a-c). Em linhas gerais, o trecho funciona como uma preparação dominante para a entrada do canto. Deve ser observado como o "acorde-bordadura" G,7.4 em (a) é, na redução (b), incorporado ao V grau da tonalidade, formando uma sonoridade bastante adensada pela presença de diversas tensões harmônicas. Setas curvas na pauta indicam condução de vozes semitonais entre notas-funções da harmonia (o que é também contemplado na cifragem analítica). No aspecto melódico, a introdução consiste em uma progressão de quarta descendente (com cada uma das notas, por sua vez, incorporando uma progressão de sexta) conectando $\hat{5}\left(A_{b}\right)$ a $\hat{2}\left(E_{b}\right)$. Um arpejo ascendente a partir desse ponto encontra a nota $C(\hat{7})$, que é então prolongada, tornando-se a Kopfton $\hat{7}$ (em antecipação ao início da melodia do canto, uma oitava abaixo). ${ }^{22} \mathrm{~A}$ análise da terceira camada sugere que a oitava $\mathrm{C}_{4}-\mathrm{C}_{5}$, em um nível mais básico, poderia ser particionada em dois trítonos (denotados como $\operatorname{Tr}_{0-6}$ e $\operatorname{Tr}_{6-0}$ ), o que introduz um elemento de vital importância para a organização de alturas na canção.

22 Não deve passar despercebido o potencial impacto dessa primeira divergência mais profunda em relação aos preceitos schenkerianos. Afinal, a ideia de que a sensível (suportada pelo acorde tônico, como se verá) possa exercer a função de nota primordial de uma estrutura musical não possui precedentes no repertório da prática comum. 
(a)

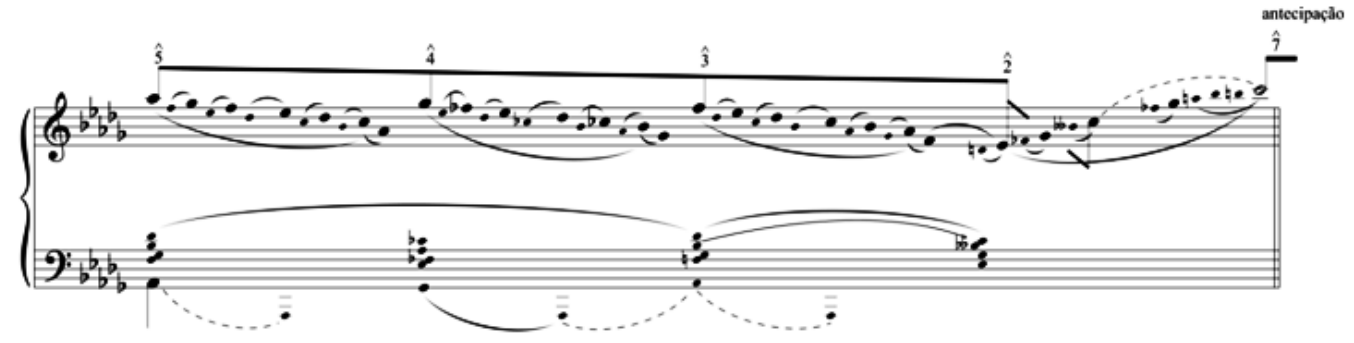

$\mathrm{A}, 477_{9}^{13} \quad \mathrm{G}, 477_{9}^{13} / \mathrm{Ab} \quad \mathrm{A}, 477_{9}^{13}$

(b)

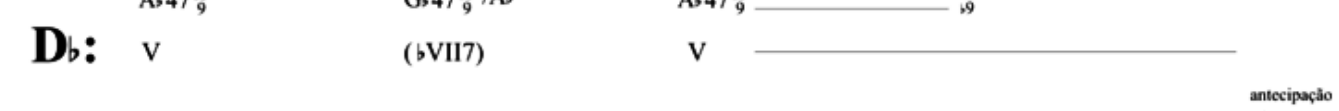

(b)

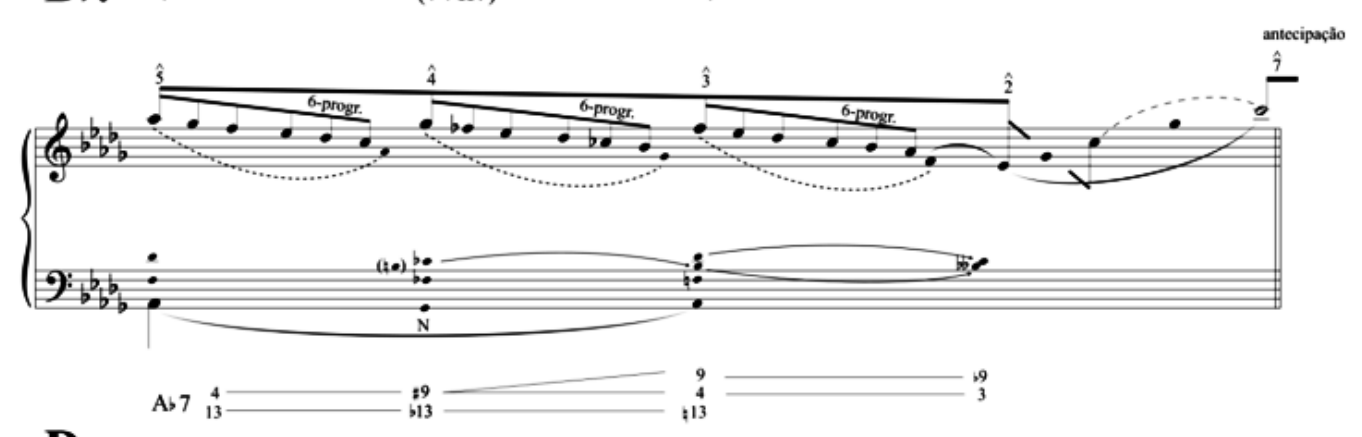

(c)

Db: $\mathrm{v}$

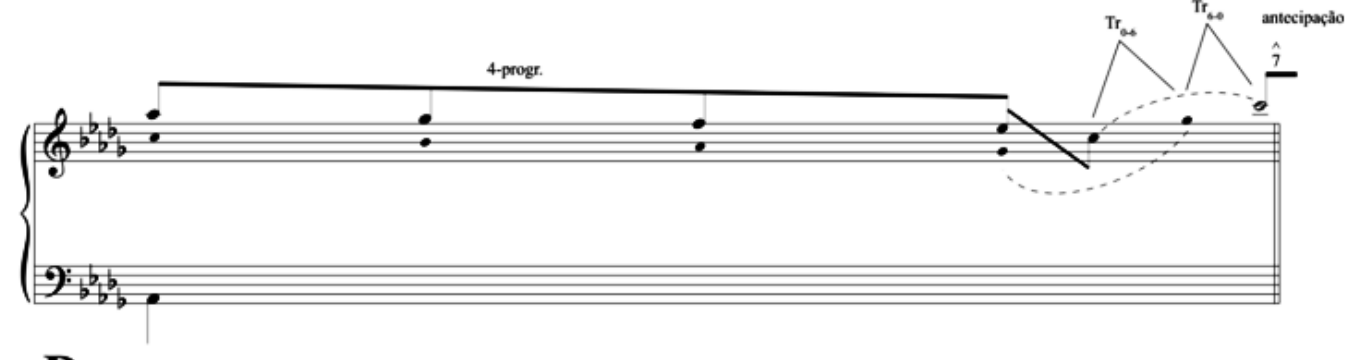

Db: v

Fig. 2: Eu te amo - análise schenkeriana da introdução (c.1-8): camada 1 (a); camada (2 (b); camada 3 (c).

\subsection{Estrofe A}

Os eventos estruturais mais relevantes da primeira estrofe (A) são apresentados na Fig. 3. A análise schenkeriana em primeira camada (a) revela que os versos são dispostos na configuração "modelo com duas sequências", envolvendo dois planos melódicos distintos. O mais superficial, destacado pelas áreas sombreadas, consiste em progressões cromáticas descendentes delimitadas por intervalos de trítono, formados por classes de alturas distintas. Propondo uma melhor visualização da interação das três progressões em relação ao campo das classes de alturas, elas são dispostas geometricamente em clockfaces (em b). ${ }^{23}$ Tomadas em conjunto, abrangem quase a totalidade cromática, excluindo-se apenas a classe de altura $\mathrm{D}$; (como indicado nos três círculos). 
No plano imediatamente superior, os eventos melódicos delineiam um tetracorde descendente formado por escala de tons inteiros a partir da Kopfton, o que é enfatizado por suas posições métricas, pelo contexto harmônico e pelo próprio texto, já que a chegada de tais notas coincide com sílabas de apoio de cada verso. ${ }^{24}$ Contrariamente ao que se observa em análises schenkerianas do repertório clássico-romântico, os quatro pontos melódicos formam com os acordes que os suportam dissonâncias "estáveis" (sétimas maiores), o que dá ainda mais consistência ao seu papel estrutural.

Em termos superficiais, a harmonia do trecho é construída especialmente com acordes não diatônicos ao campo tonal de Ré bemol maior, provenientes de substituições tritônicas de dominantes secundários (conhecidos como "subV" no jargão da música popular) e da classe dos empréstimos modais (acordes não diatônicos incorporados ao campo tonal pelas relações de afinidade com regiões tonais vizinhas). Os acordes selecionados são claramente subordinados à linha de baixo descendente e cromática que os suporta, uma característica marcante do tratamento harmônico de Jobim, ${ }^{25}$ bem como à intenção de posicionar, como espécies de pilares, acordes maiores com sétima maior e quinta aumentada sob cada uma das quatro notas de apoio acima descritas.

\footnotetext{
24 Sílabas tônicas finais dos versos 1, 2 e 3, além da sílaba inicial ("Ah") da estrofe, como indicadas pelas molduras no texto acima da pauta da Fig. 3.

25 Estratégia composicional bastante recorrente em sua obra, presente em maior ou menor medida em canções como Samba de uma nota só, Corcovado, Insensatez, Inútil Paisagem, Águas de Março, entre outras.
} 
(a)

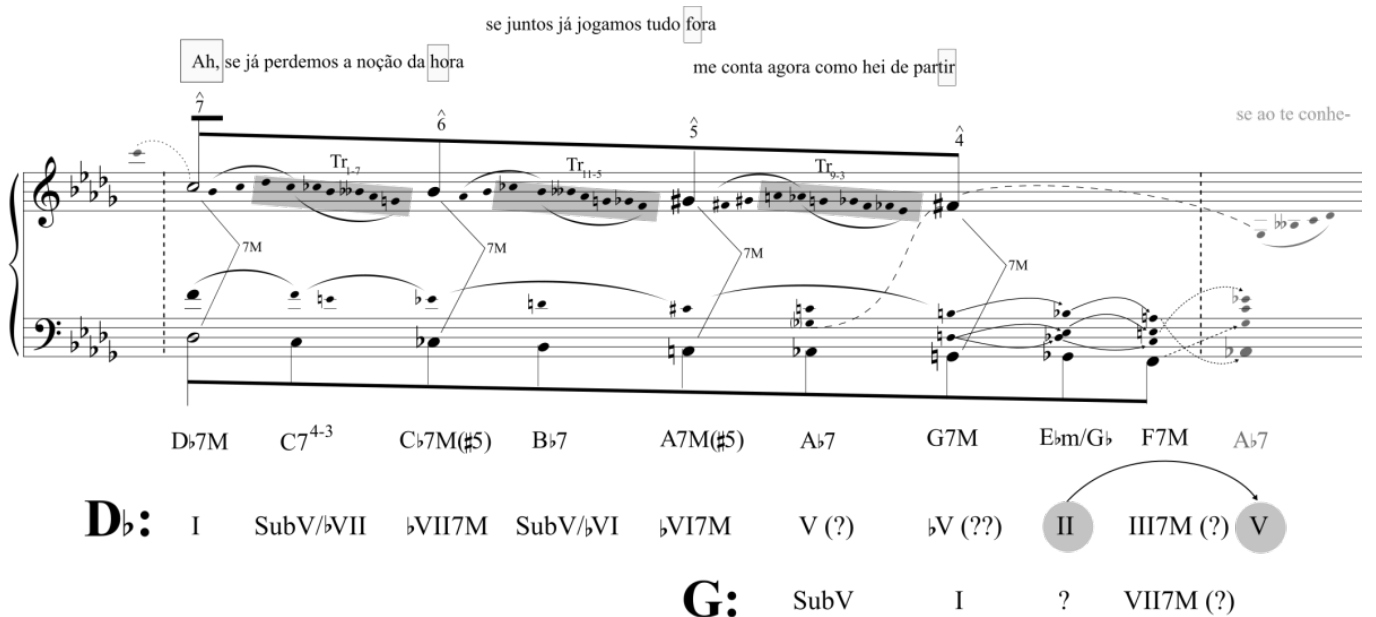

(b)

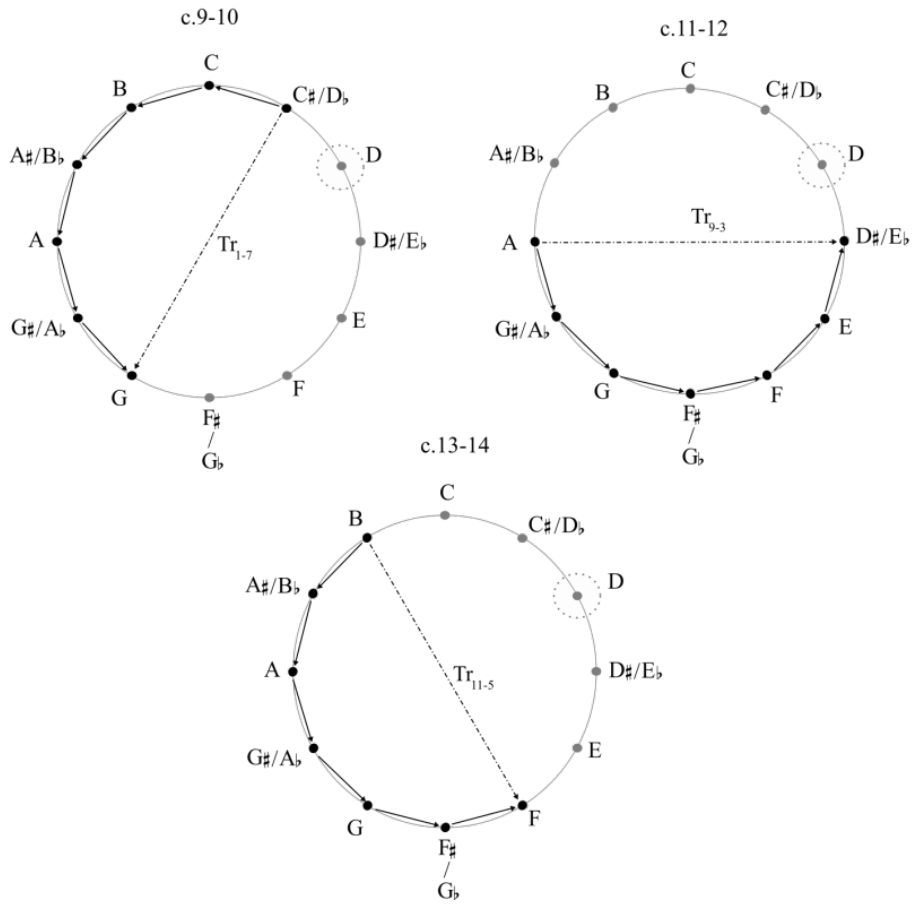

Fig. 3: Eu te amo - análise schenkeriana da estrofe A (c.9-18), considerando a camada 1 (a);

Disposição em clockface das três progressões cromáticas em trítono demarcadas no gráfico superior (b).

A análise harmônica proposta neste artigo opta por interpretar os cinco acordes iniciais como pertencentes a Ré bemol, embora fosse também perfeitamente válido tratar os acordes-pilares $C, 7 M(\$ 5), A 7 M(\$ 5)^{26}$ não como empréstimos modais (,VII7M e ,VI7M), mas como tônicas de duas modulações sequenciais (Ré bemol $\rightarrow$ Dó bemol $\rightarrow$ Lá bemol), conduzidas pelos apoios na escala de tons inteiros. De toda maneira, o acorde que se segue ao trecho inicial $(A, 7)$ exerce um papel de pivô na progressão, pois ao mesmo tempo que corresponde

26 Neste e em outros pontos semelhantes, o recurso da equivalência enarmônica foi empregada em prol de uma notação mais simples e clara. Tal decisão se apoia no fato de que as relações simétricas, que são abundantes na canção, neutralizam ou mesmo anulam (como é aqui o caso) a necessidade da distinção precisa entre eventos de alturas. 
à dominante da tonalidade referencial, pode ser também interpretado como o substituto tritônico da dominante (subV) referente à tonalidade diametricamente oposta a Ré-bemol, isto é, Sol maior, para onde se dirige efetivamente. ${ }^{27}$

Após atingir o final da parte cantada, o motto harmônico, conduzido pelo baixo cromático, mantém-se ainda em atividade, alcançando uma nova estação da escala de tons inteiros, F7M, acorde que, pelo princípio da inércia, pode ser interpretado como I grau de Fá maior. Alternativamente, sob a perspectiva da tônica central, o mesmo acorde pode ser visto como resultante da confluência de movimentos cromáticos de vozes internas (como sugerem as setas curvas na figura) que conectam $\mathrm{E}, \mathrm{m} / \mathrm{G}$, (II grau) a A,7 (aqui como um $\mathrm{V}$ de facto), produzindo um desfecho em cadência à dominante, em preparação para a próxima estrofe.

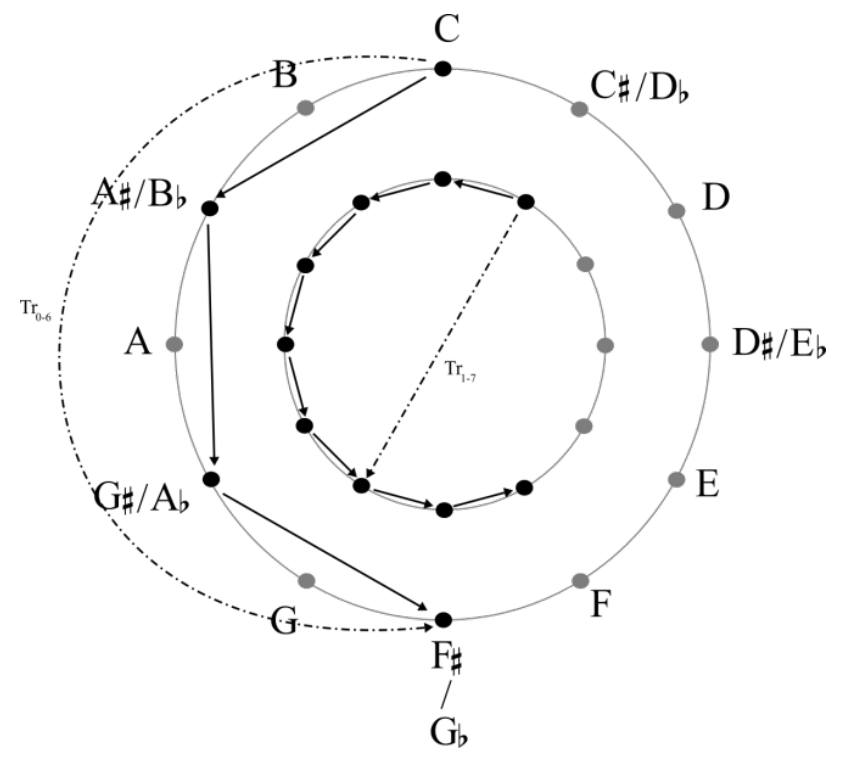

Fig. 4: Representação geométrica das relações intervalares de melodia (círculo externo) e baixo (círculo interno) na estrofe $A$.

Uma representação geométrica das relações intervalares mais essenciais da melodia e linha de baixo é apresentada na Fig. 4. O gráfico, que toma como modelo um esquema semelhante proposto por Dmitri Tymoczko (2011, p. 147, fig. 4.9.5), consiste em dois clockfaces concêntricos que representam os campos de classes de alturas relacionados aos eventos melódicos (dispostos no círculo externo) e aos baixos (círculo interno). Setas cheias indicam movimentos contíguos, setas em traço-ponto correspondem a relações mais profundas. As duas lógicas são essencialmente distintas, relacionadas a diferentes coleções simétricas (tons inteiros e cromática), porém compartilham em alto nível um âmbito tritônico: $\operatorname{Tr}_{0-6}$ (na melodia) e $\operatorname{Tr}_{1-7}$ (baixo, neste caso considerando o trecho correspondente à harmonização da linha vocal). Nessa concepção, a linha melódica descreve a metade de um hexágono (na forma de um polígono regular aberto), denotando sua simetria interna.

27 Tal estratégia de modulação entre polos tonais tomando proveito das propriedades inerentemente ambíguas da qualidade acordal X7 é descrita por Arnold Schoenberg (2001, p. 343-380) entre seus comentários sobre acordes errantes, ou seja, acordes com múltiplas funcionalidades. 


\subsection{Estrofe B}

A estrofe B é analisada em primeira redução na Fig. 5. Novamente, observa-se uma coincidência entre os destaques métricos melódico-harmônicos e textuais, o que permite uma estratificação clara da linha do canto em dois planos. A despeito disso, a estrofe contrasta com a anterior em respeito ao ambiente harmônico: enquanto A é subordinada a uma organização primordialmente simétrica, resultando em modulações, a estrofe B é essencialmente assimétrica e circunscrita ao âmbito diatônico de Ré-bemol maior.

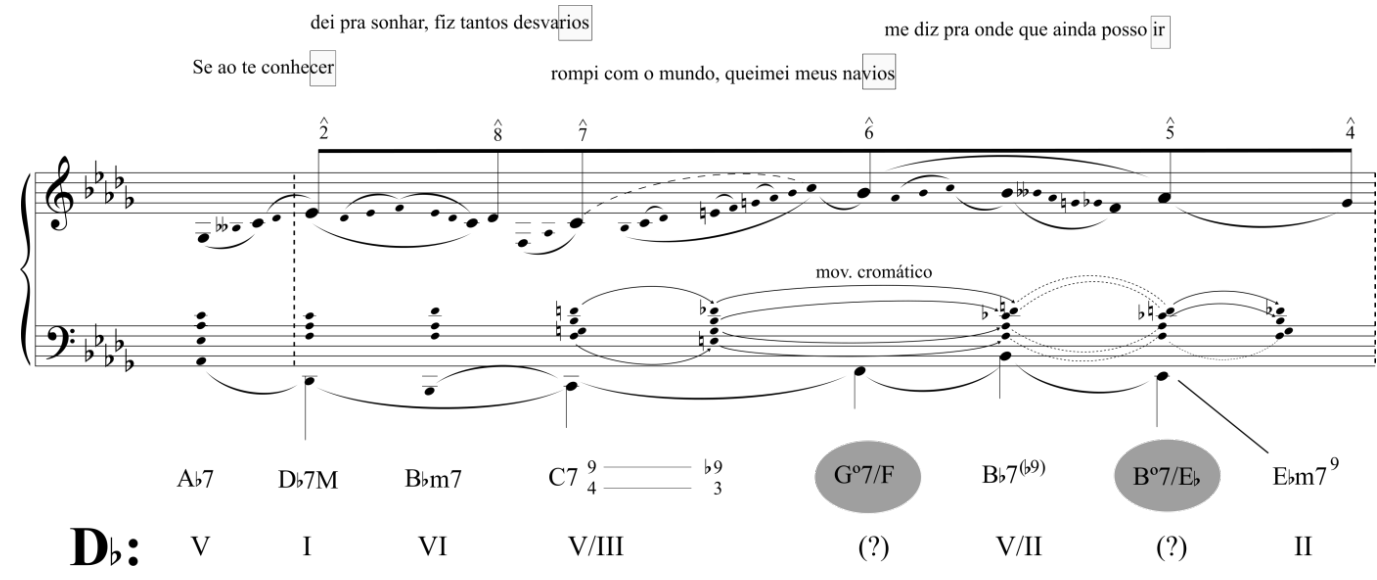

Fig. 5: Eu te amo - análise schenkeriana da estrofe B (c.18-27), considerando a camada 1.

No entanto, como indicado pelas molduras elípticas e pelas interrogações, dois acordes híbridos $^{28}\left(\mathrm{G}^{\circ} / \mathrm{F} \mathrm{e} \mathrm{B}^{\circ} / \mathrm{E}_{b}\right)$ parecem resistir à análise funcional. A Fig. 6 propõe explicar suas possíveis origens como resultantes de transformações a partir de um modelo caracterizado pelo encadeamento de três dominantes secundárias consecutivas. Para isso, considere incialmente a hipotética progressão em (a), por conveniência escrita em semibreves (um acorde por compasso) em voicings do tipo "4+1", de maneira que o baixo seja isolado da harmonia. A progressão é então transformada em (b), a partir de duas simples operações, o que gera os acordes híbridos em questão: (1) supressão das notas da "mão direita" (mas não a do baixo) do c.2, referentes ao acorde F7, de tal modo que as vozes do acorde anterior (C7) sejam mantidas; (2) duplicação do c.3, substituindo seu baixo por uma antecipação do baixo seguinte $\left(E_{b}\right)$. Emoldurados ao lado de cada caso são analisadas, em formato de grafo, as conduções dos acordes das respectivas "mãos direitas". ${ }^{29}$ A comparação dos dois esquemas deixa evidente a maior eficiência e economia da versão transformada (b), ${ }^{30}$ o que pode talvez justificar a harmonização desse trecho por Jobim. Em suma, é possível considerar os

28 Um acorde híbrido consiste na combinação de uma estrutura harmônica tercial superior (em geral, uma tríade perfeita) com um baixo que não pertence ao acorde (por exemplo, C/D). Acordes híbridos, via de regra, resultam em uma sonoridade tensa, porém homogênea, não demasiadamente dissonante. $O$ conceito não deve ser confundido com o de bicorde, a sobreposição de dois acordes (comumente, bastante distintos entre si, como o famoso "acorde Petrouchka" - F\#/C - presente na obra homônima de Stravinsky).

29 Os rótulos "S", "C", "T" e "B" (como "soprano", "contralto", "tenor" e "baixo") se referem às posições relativas das vozes dos acordes.

30 Numa simples contabilização dos valores absolutos dos movimentos melódicos, tem-se: 14 (a) e 8 semitons (b). 
dois acordes híbridos como derivados de manipulação das escalas temporais das camadas da harmonia e do baixo, que se comportaram nesses pontos como placas tectônicas independentes.

(a)

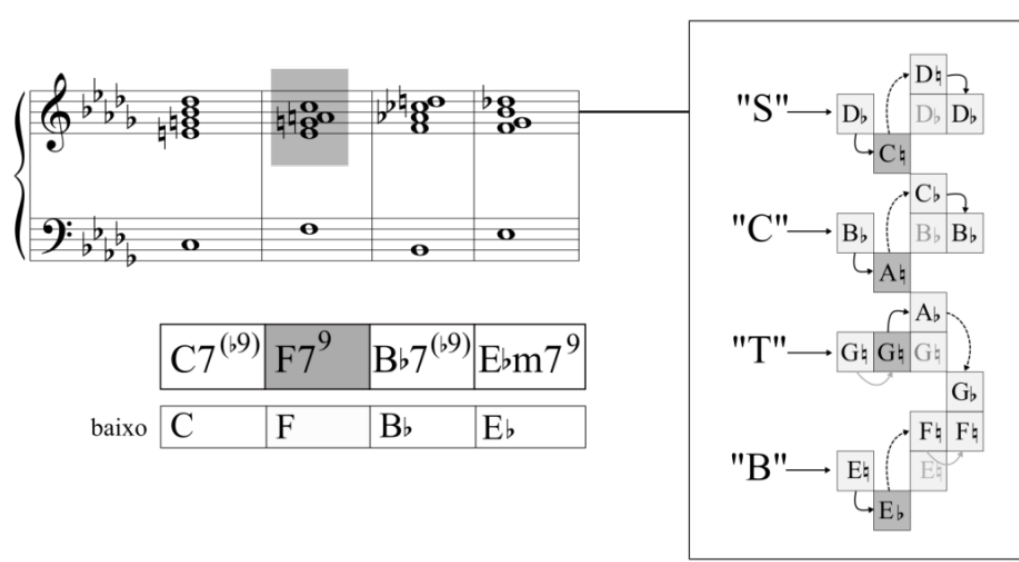

(b)

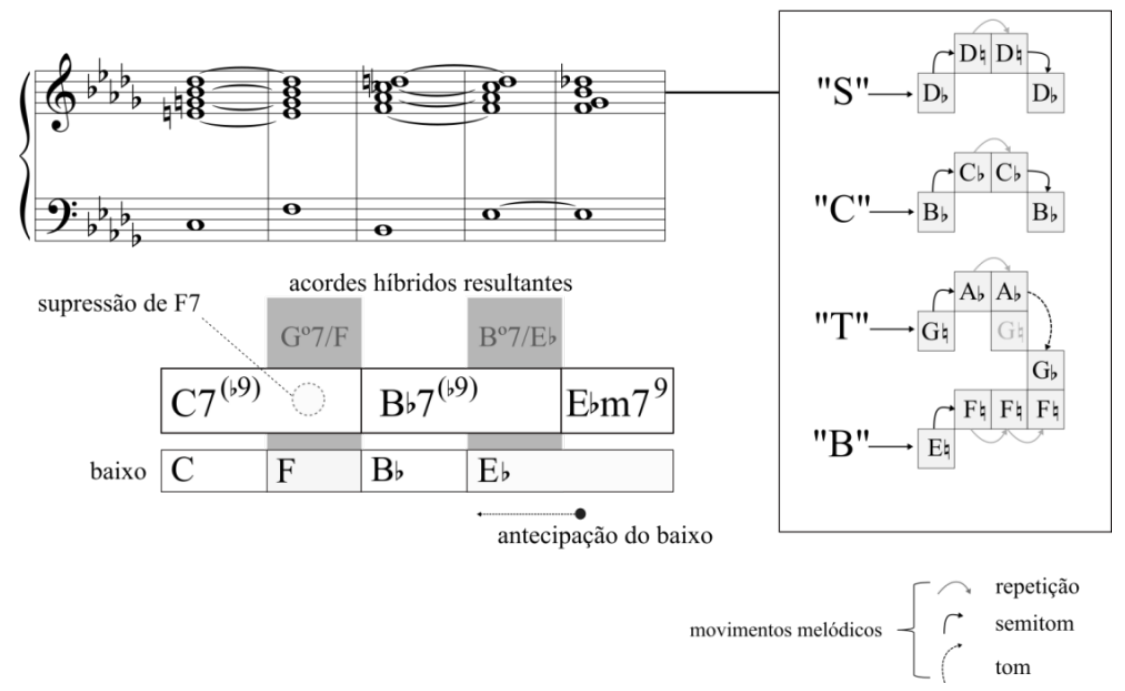

Fig. 6: Possivel explicação funcional para os acordes híbridos da Fig. 5: (a) versão hipotética; (b) versão transformada e definitiva. Os símbolos "S" (soprano), "C" (contralto), "T" (tenor) e "B" (baixo) referem-se à ordem das quatro vozes harmônicas.

Essa reinterpretação harmônica é incorporada na próxima redução da estrofe B, apresentada na Fig. 7a. 
(a)

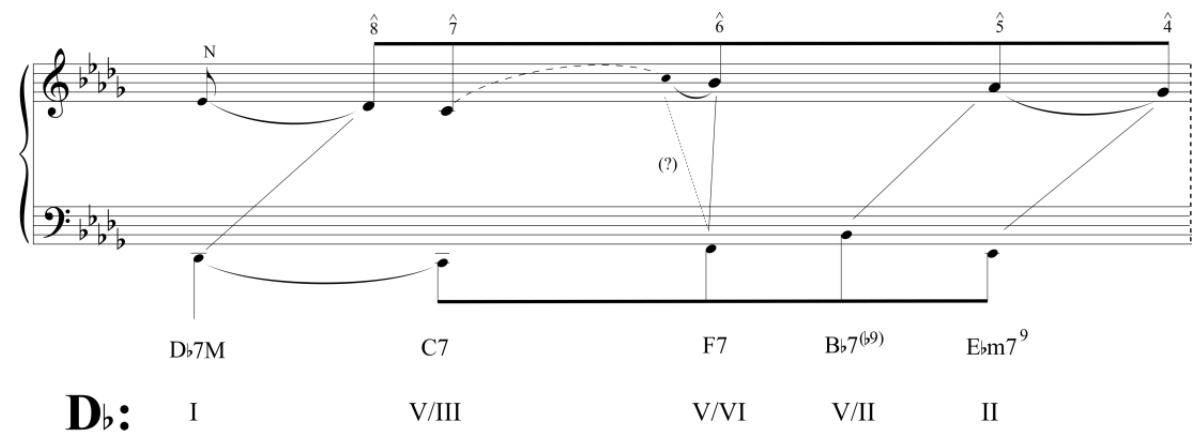

(b)

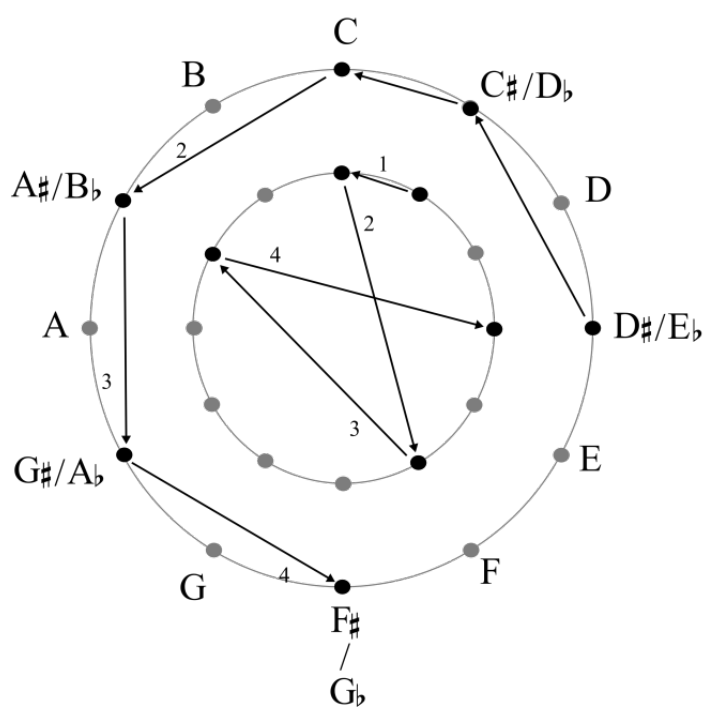

Fig. 7: Redução em segunda camada referente ao gráfico da Fig. 5 (a) e sua representação geométrica (b).

Sob tal perspectiva, fica bem explícita a polarização do Il grau pela cadeia de dominantes secundários (indicada pela barra ligando os baixos $\mathrm{C}-\mathrm{F}-\mathrm{B}_{\text {, }}$ ) como o alvo funcional da passagem. ${ }^{31} \mathrm{Em}$ relação aos eventos melódicos, é possível considerar que, diferentemente do que acontece na estrofe $A$, a dissonância (nona maior) formada com a fundamental do acorde $\mathrm{D}, 7 \mathrm{M}$ resolveria neste nível mais profundo no dobramento da fundamental do acorde, o que faz com que o trecho apresente nesse aspecto uma configuração schenkeriana mais próxima aos moldes tradicionais. Cada nota da linha diatônica descendente é então respaldada por um dos acordes que foram retidos na redução. ${ }^{32} \mathrm{O}$ diagrama geométrico referente ao trecho (em b) captura visualmente o contexto diatônico da estrofe, com setas cruzadas no círculo interno (modelando movimentos de quartas ascendentes no baixo) e o polígono irregular (aberto, no caso) no círculo externo, correspondendo a movimentos escalares diatônicos.

\footnotetext{
310 que é inspirado em convenção proposta por Forte (1995).

32 Restando apenas uma indecisão sobre qual evento melódico deve ser associado a F7: ^8 (como sua quinta) ou ^ 6 (como quarta, o que tornaria o acorde um dominante com quarta suspensa).
} 
(a)

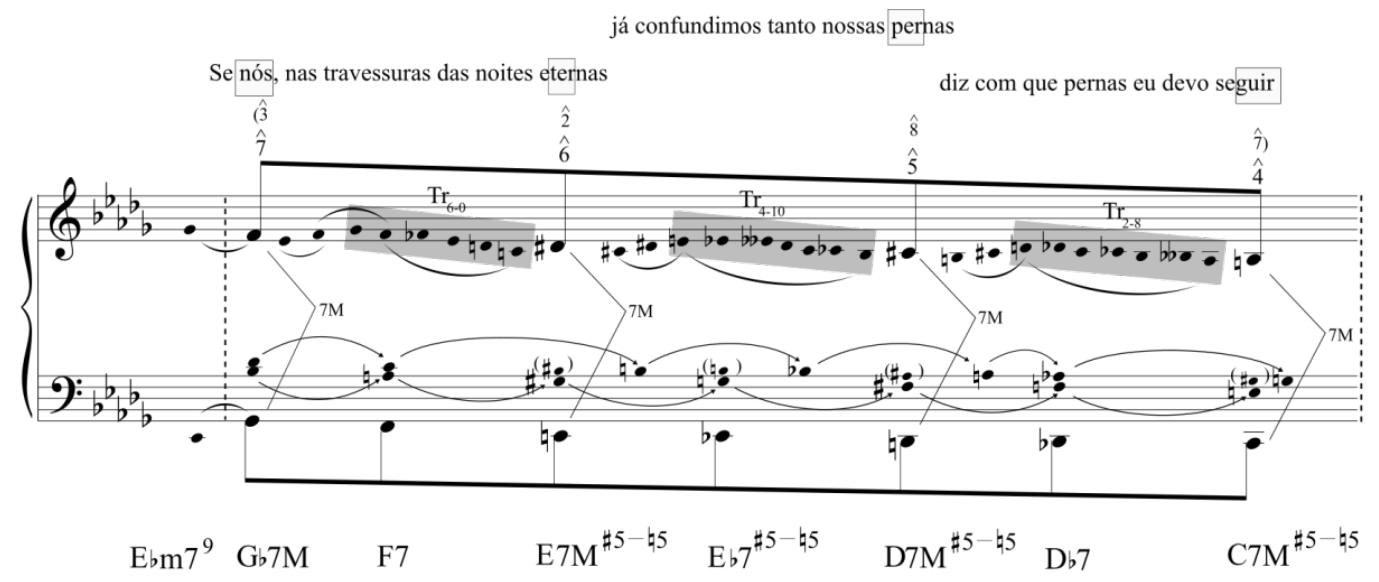

C: $\quad$ SubV I (?)

(b)

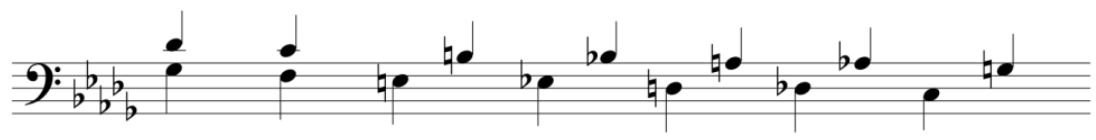

(c)

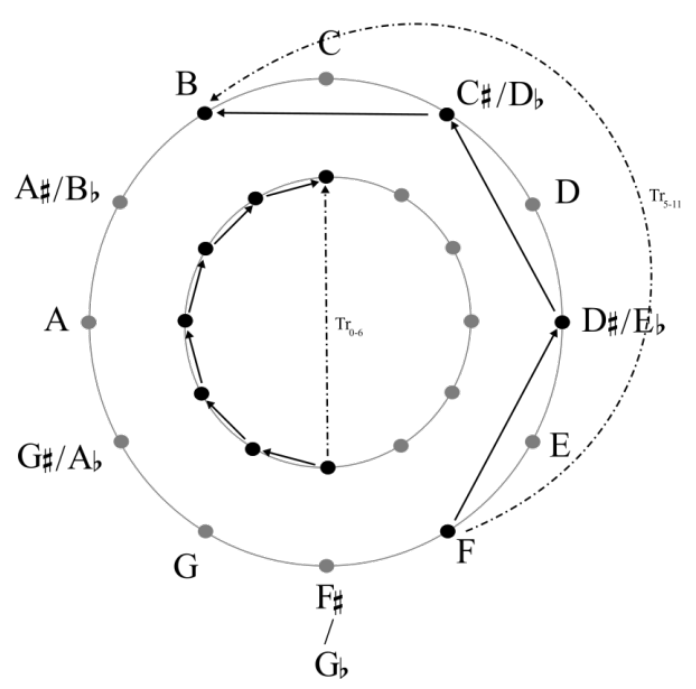

Fig. 8: Eu te amo - análise schenkeriana da estrofe C (c.18-27), considerando a camada 1 (a); relação "tectônica" entre linha cromática de quintas acordais e o baixo (b); representação geométrica das relações intervalares da melodia e do baixo. 


\subsection{Estrofe C}

Como mencionado na introdução do artigo, a estrofe C retoma a estrutura da estrofe A, porém transposta por quarta ascendente e apresentando duas pequenas diferenças em relação ao original (Fig. 8). Uma delas é a supressão da extensão da harmonia, após o final da linha do canto. Menos evidentes são as inclusões de movimentos contrapontísticos em acordes de quinta aumentada, na forma " $\$ 5-45$ ", criando uma nova linha cromática interna, em relação de quintas "tectônicas" com o baixo (ambas destacadas em b). ${ }^{33}$

Numa visão funcionalista mais global, é possível considerar a seção C como um movimento em direção à subdominante estrutural da tonalidade, uma estratégia comum em uma vasta parte do repertório tonal, com a finalidade geral de prover contraste climático a partir de um afastamento centrífugo (ainda que contido às fronteiras diatônicas). Por essa razão, a análise harmônica identifica o primeiro acorde da estrofe (G,7M) como IV e não I (de Sol-bemol maior). No entanto, os eventos subsequentes, por força do paralelismo em relação ao já ocorrido, pressionam para um redirecionamento da análise, levando à trajetória modulatória correspondente àquela da estrofe inicial, desta vez, conectando os polos tritônicos Sol-bemol e Dó.

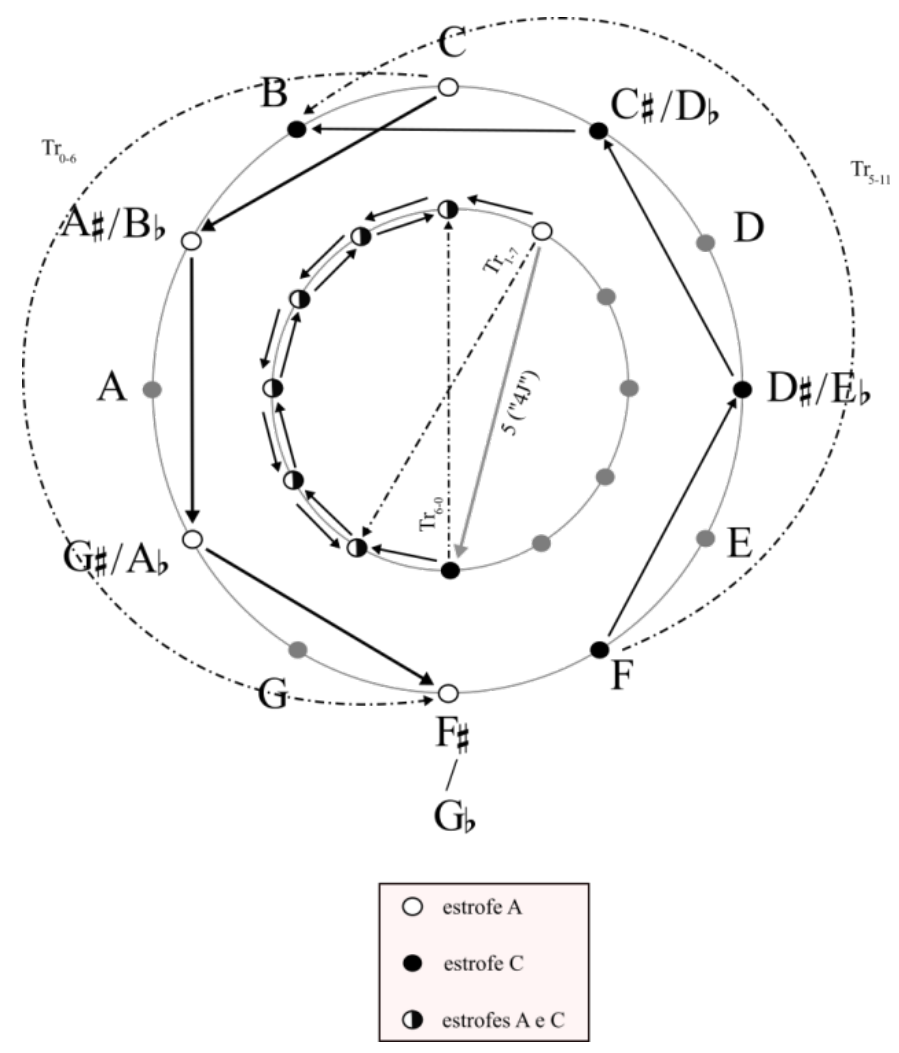

Fig. 9: Sobreposição das representações geométricas das estrofes A e C. 
A Fig. 9 fornece uma comparação entre as representações geométricas das estrofes $\mathrm{A} e$ $C_{1}{ }^{34}$ sobrepondo-as, revelando uma organização simétrica de alta sofisticação e complexidade. ${ }^{35}$ No círculo externo, da melodia, observa-se um perfeito espelhamento dos eventos (envolvendo, em cada estrofe, quatro notas das duas coleções da escala de tons inteiros) a partir de um eixo de simetria que passa entre as classes de alturas Dół-Sił e Fáł-Sol). ${ }^{36}$ Já no círculo interno, dos baixos, as duas estrofes compartilham o segmento cromático Dół-Sola (ordenados em sentidos opostos), tendo como exclusivas as classes de alturas Ré, (na estrofe A) e Sol, (estrofe C), que se conectam pela classe intervalar 5 (quarta justa), evidenciando a relação em alto nível tônica-subdominante entre as duas estofes.

\subsection{Estrofe D}

De acordo com o que já foi discutido, a estrofe $D$ representa um momento de mudança no argumento poético, retratando a tomada de consciência do protagonista em relação à ruptura amorosa. Como será discutido, o tratamento musical dado por Jobim a esse contexto parece justamente reforçar esse caráter contrastante.

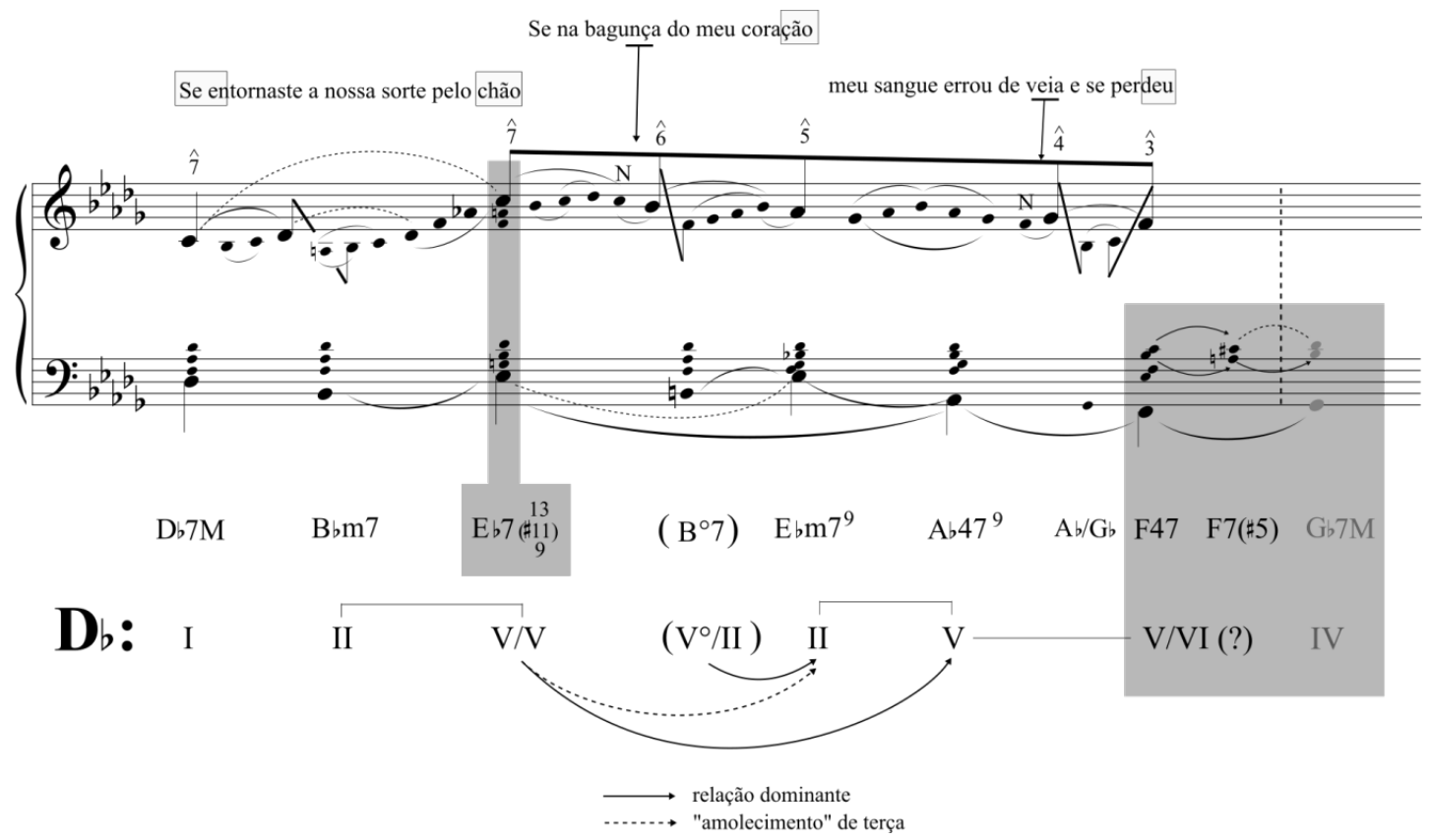

Fig. 10: Eu te amo - análise schenkeriana da estrofe C (c.35-42).

34 Por simplicidade visual, a extensão da linha do baixo após a finalização da linha do canto $(\mathrm{G} \rightarrow \mathrm{G}, \rightarrow \mathrm{F})$ na estrofe $A$ foi desconsiderada neste esquema.

35 A simetria se torna mais notável se for aplicada uma rotação de $30^{\circ}$ no sentido horário apenas sobre os pontos referentes à melodia da estrofe C, resultando em um hexágono completo (representando a divisão da oitava em doze partes iguais).

36 Mais precisamente, um eixo de simetria inversional de soma 11, de acordo com preceitos da Teoria dos Conjuntos de Classes de Alturas. Para maiores detalhes, ver Straus (2005, p.47-48; 133-137). 
A Figura 10 apresenta uma análise em primeira camada da estrofe. De início, observa-se o estabelecimento de um novo nível métrico no texto, intermediário (o que é indicado pelas sílabas sublinhadas), que são suportadas por apojaturas em relação a notas de posição hie-

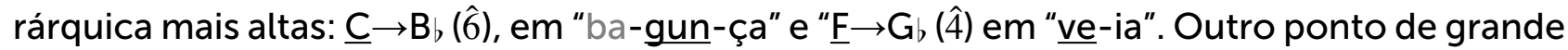
interesse e de especial associação entre poesia e música diz respeito ao final do primeiro verso (primeiro destaque em cinza). Vários elementos musicais parecem convergir para enfatizar esse ponto climático: (1) pela primeira vez, há uma inversão de tendência descendente que predomina no contorno da linha melódica do canto, com uma ascenção rápida (e claramente dramática) em arpejo abrangendo uma oitava (remete vagamente ao gesto instrumental que conclui a introdução - ver Fig. 2); (2) o suporte harmônico nesse ponto - na cifra alfanumérica

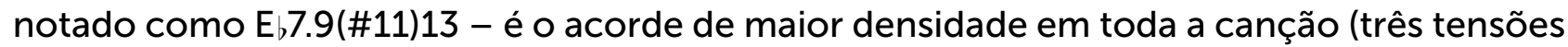
acrescentadas à tétrade básica); (3) a nota da melodia é a própria Kopfton 7 , representando um acréscimo do grau de dissonância em relação à fundamental do acorde (décima terceira), se comparado com o do acorde inicial da estrofe, no qual exerce a função de sétima maior. Tudo isso parece estar a serviço de uma "pintura sonora" do texto poético nesse momento ("Se entornaste a nossa sorte pelo chão"), a partir de uma interpretação musical do estado de profunda confusão mental do protagonista: nesse sentido, a palavra "chão" é musicada com um enfático movimento ascendente (como que retratando uma súbita perda de referencial físico-psicológico) e sublinhada dramaticamente pela tensão melódico-harmônica. A lenta descida da linha subsequente (que não retoma, contudo, o nível inicial) se sintonizaria com uma mais suave mistura de dor, perplexidade e lembrança, como é sugerido pelo texto.

Em seu perfil geral funcional, de natureza centrípeta, a harmonia da estrofe $D$ apresenta relações de afinidade com a da estrofe B. Como as setas abaixo da análise sugerem, o centro de gravidade da progressão consiste basicamente em um encadeamento $\mathrm{V} / \mathrm{V} \rightarrow \mathrm{V}$, cujos acordes-núcleos são embelezados pelo recurso de "Il relativos" e soldados através de um procedimento denominado "amolecimento" de terça. ${ }^{37}$ A esperada resolução sobre o acorde tônico em primeira inversão (induzida pela sétima no baixo do V grau) é, no entanto, frustrada com sua surpreendente substituição por $F 47$ (ver a segunda área destacada na Fig. 10). A função do bloco formado por esse acorde enigmático e sua continuação contrapontística, $\mathrm{F7}(\sharp 5)$, fica mais clara ao percebermos que prepara parcimoniosamente a retomada de G,7M, o ponto de partida do próximo trecho. ${ }^{38} \mathrm{~A}$ Fig. 11 propõe duas possíveis significações alternativas para o acorde em questão, ambas assumindo o papel de preparação subdominante. A primeira opção mantém a cifra alfanumérica original, o que torna o acorde em questão uma espécie de versão espelhada de um subV (propõe-se aqui, como um neologismo funcional, a cifra analítica "anti-subV"/IV). A segunda interpretação reescreve a nota C $\#$ como D, e considera como implícita a presença da nota $C$, como sétima do acorde dominante secundário aumentado do IV, em primeira inversão, sendo então cifrado como $\left.D, 7(\sharp 5)^{9} / F\right)$. A despeito dessas mudanças, a alternativa (b) é funcionalmente mais simples e, portanto, mais adequada em uma análise estrutural.

37 Consiste basicamente em uma técnica muito empregada na prática jazzística e bossa-novista, de transformar uma dominante secundária (de qualidade X7) em "II relativo" (Xm7) associado a outra dominante, através do abaixamento da terça. 
(a)

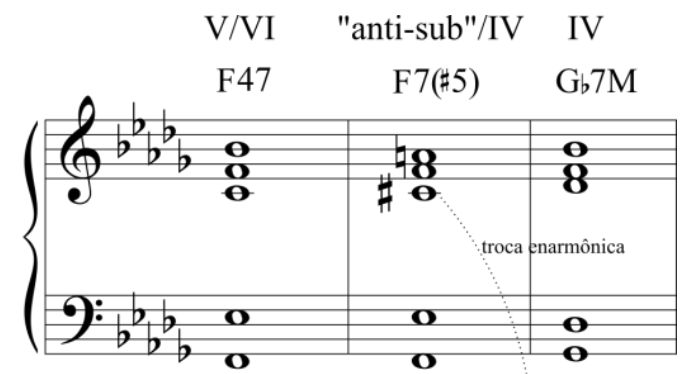

(b)

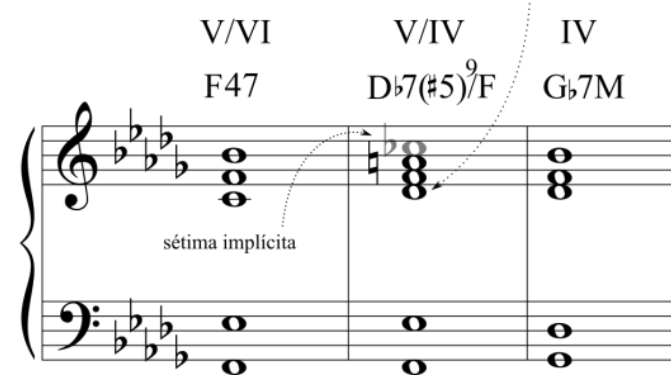

Fig. 11: Alternativas funcionais para o acorde final da estrofe D.

A redução subsequente (Fig. 12a) incorpora essa interpretação funcional. O diagrama geométrico (b) reforça o parentesco entre as estrofes $B$ e $D$, que poderiam ser descritas em termos dos comportamentos gráficos de suas melodias (polígonos abertos irregulares) e linhas de baixo (descrevendo cordas dentro do círculo interno). ${ }^{39}$

(a)

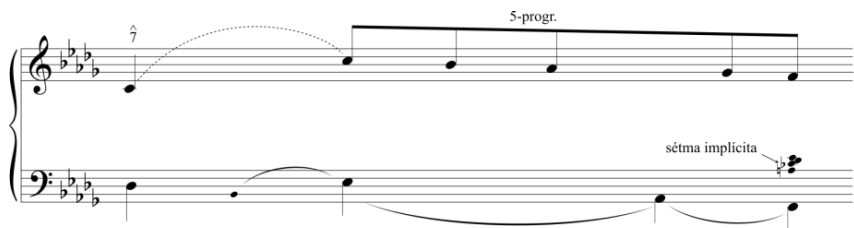

D.: I $\quad$ II $\quad$ V/V

V/IV

(b)

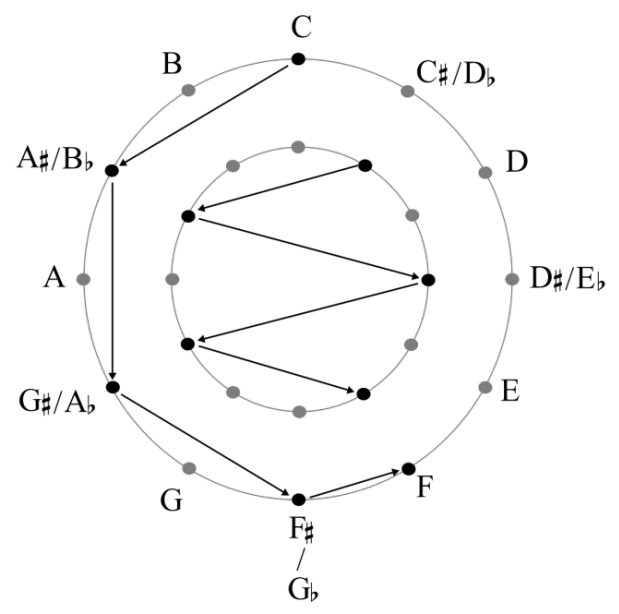

Fig. 12: Redução em segunda camada referente ao gráfico da Fig. 10 (a) e sua representação geométrica (b). 


\subsection{Uma perspectiva global}

Tendo sido concluídas as análises individuais das estrofes que apresentam conteúdos musicais distintos, faz-se agora necessário um exame global de toda estrutura da canção, de modo a evidenciar a interação dos planos e relações que a caracterizam. A Fig. 13a combina em um único gráfico as reduções da introdução e das quatro estrofes, a partir dos dados analíticos obtidos. Isso permite afirmar que três relações intervalares exercem papel central na organização de alturas na peça:

- Tritônica (ic6) 40 - presente em diversos níveis das linhas melódica e do baixo. É graficamente indicada por linhas (ligaduras ou setas) em traço-ponto;

- Semitonal (ic1) - presente em conexões entre estrofes e (projetada em sua versão invertida, como 7M) nas relações entre melodia e fundamental harmônica (estrofes $A$, C, E e F). Indicada por linhas/ligaduras/setas cheias em preto;

- Quartal (ic5) - presente, em alto nível, na relação Tônica-Subdominante e, mais próxima à superfície, nos encadeamentos de dominantes secundários consecutivos. Indicada por linhas/ligaduras/setas cheias em cinza. ${ }^{41}$

40 Ou seja, classe intervalar 6 (ic6 na abreviatura mais difundida, a partir do original em inglês, interval class). Uma classe intervalar representa da maneira mais compacta todas as manifestações possiveis dos intervalos membros da classe, através de expansão (por soma de oitavas) ou inversão.

41 Também presente, embora de maneira menos estrutural entre as tonalidades de Sol e Dó maior. Agradeço ao avaliador anônimo deste artigo que apontou a possibilidade dessa relação. 
(a)
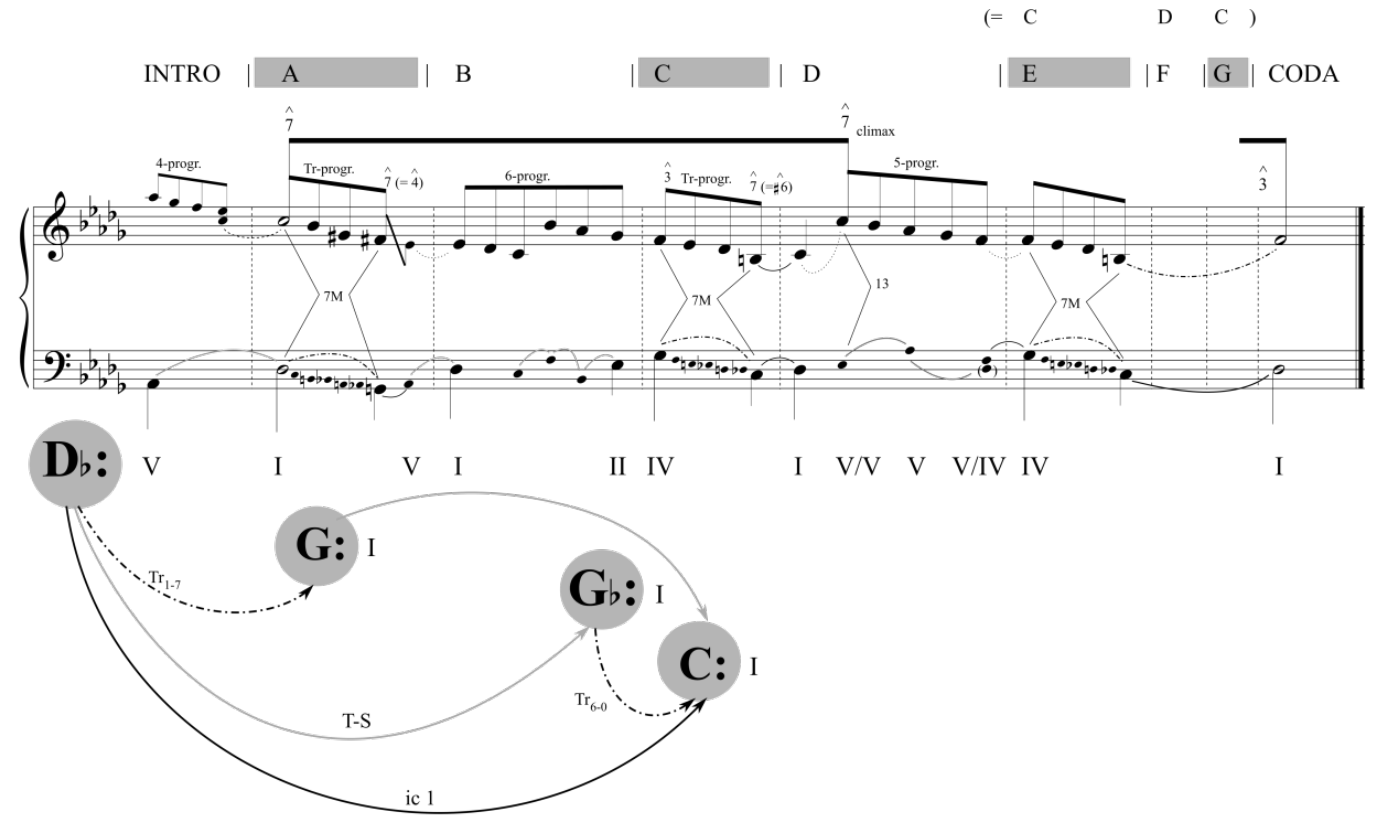

(b)

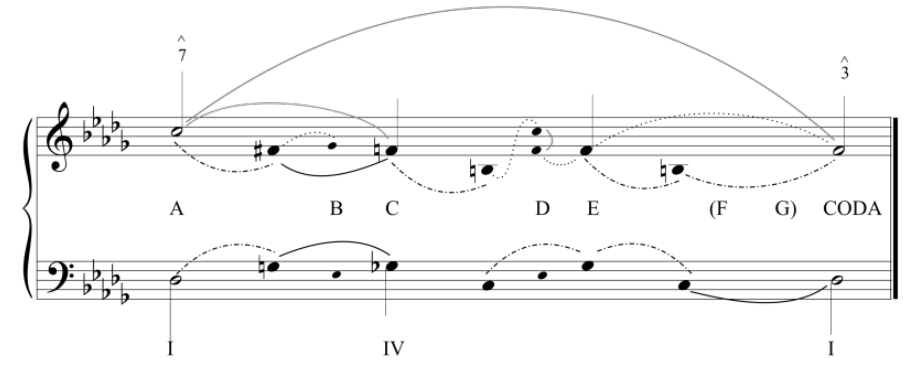

(c)

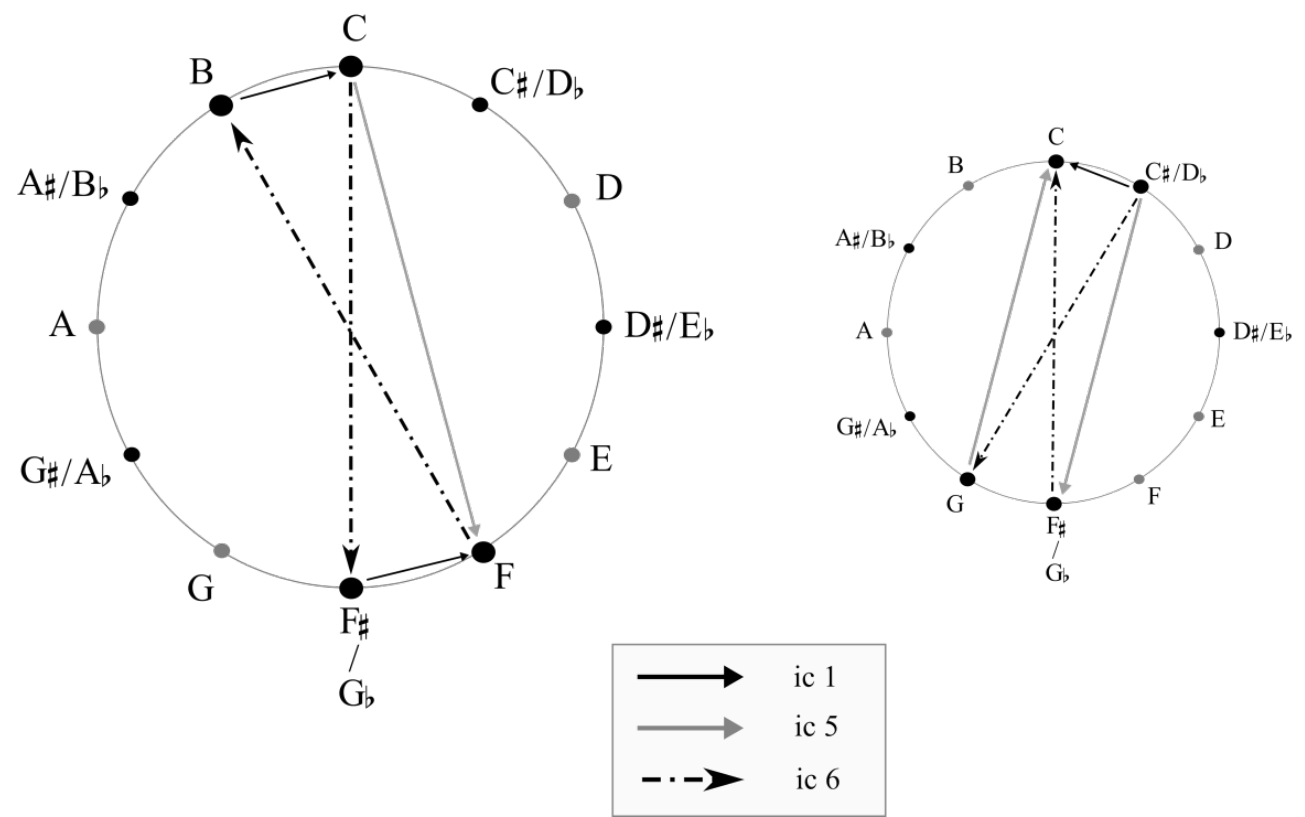

Fig. 13: Visão global da estrutura de Eu te amo (a); Redução final (b); Representação geométrica (c). 
Em termos formais, percebe-se uma alternância entre "territórios" diatônicos e centrípetos (introdução e estrofes B, D e F) e ambientados na escala de tons inteiros e de propensão centrífuga (destacados em fundo cinza sobre a pauta) nas estrofes A, C, E e G). De especial importância nesse esquema de alto nível é o processo de interação entre as quatro tonalidades (todas maiores) visitadas ao longo da canção (Ré-bemol, Sol, Sol-bemol e Dó), perfeitamente ajustado aos três eixos intervalares considerados.

A Fig. 13b propõe uma prospecção ainda mais profunda dessa análise, filtrando apenas o que pode ser tomado como mais essencial. A representação geométrica dessas relações, ${ }^{42}$ em (c), deixa ainda mais evidente a extraordinária simetria que compõe a infraestrutura de $E u$ te amo, revelando como a interação das três relações intervalares (ic1, 5 e 6) estaria presente no nível mais básico em ambas as camadas. De acordo com essa geometria, depreende-se que melodia e harmonia (representada pela linha do baixo) são construídas sobre os mesmos alicerces intervalares, diferindo apenas por uma simples rotação de $30^{\circ}$. Pelo prisma da Teoria dos Conjuntos de Classes de Alturas, ambas as configurações pertencem à mesma classe, a do tetracorde (0167), também identificado como 4-9 (na nomenclatura de Allen Forte), curiosamente uma das formações mais recorrentes na música pós-tonal, o que se deve à sua estrutura inerentemente simétrica e a suas especiais propriedades intervalares. ${ }^{43}$

\section{Considerações finais}

Este artigo propôs uma análise detalhada da canção Eu te amo, de Jobim e Buarque, focando especialmente relações intervalares simétricas, que se apresentam infiltradas em diversos níveis estruturais. A combinação de ferramentas da teoria pós-tonal com uma adaptação da análise schenkeriana às particularidades da música popular (e, especificamente, à prática jobiniana) mostrou-se bem-sucedida como estratégia metodológica para a abordagem pretendida.

A partir dos resultados obtidos, chamam especial atenção a sofisticação e a complexidade estrutural da peça, apresentando-se em um grau de magnitude incomum, senão inédito, no contexto das canções populares. É particularmente notável o fato de que, a despeito da existência de trechos que abertamente desafiam a funcionalidade tonal, tanto pelo intenso cromatismo quanto pela organização melódico-harmônica calcada na escala de tons inteiros (inclusive em níveis próximos à superfície musical), a peça não causa, de modo algum, estranhamentos ao ouvinte médio, tonando-se uma das canções mais líricas, pungentes e memoráveis do repertório da música popular brasileira.

A análise trouxe para o primeiro plano de interesse o trio de relações intervalares 1, 5 e 6 como candidatos a eixos estruturais em Eu te amo. A comparação com duas outras análises semelhantes de obras jobinianas previamente realizadas pelo presente autor (ALMADA, 2010, 2012) revela dois importantes pontos de contato nesse sentido: ambas as relações semi-

42 De modo a tornar mais clara a visualização da figura, os círculos referentes à melodia e ao baixo são dispostos lado a lado e não concentricamente.

430 tetracorde 4-9 contém em seu vetor intervalar (200022) duas ocorrências de cada uma das classes intervalares 1, 5 e 6. 
tonal e quartal são profundamente infiltradas nas estruturas primordiais das três canções, manifestando-se também em estratos médios e superficiais. Por outro lado, o destaque da relação tritônica é observado apenas no presente caso, tornando-se seu principal elemento distintivo. Consequentemente, a investigação sobre outras ocorrências similares na obra do compositor mostra-se como uma promissora linha para pesquisas futuras.

Deve-se ainda acrescentar que, embora não intensamente como em outros exemplares do cancioneiro jobiniano, ${ }^{44}$ há no caso presente - como demonstrado ao longo da análise - uma preocupação pela interação entre texto e música (integradas em melodia, harmonia e linha de baixo). Isso se denota tanto em níveis mais abstratos, considerando o argumento geral da obra (a lamentação e o desespero sendo retratados pelo contorno musical quase que continuamente descendente e cromático), quanto no caso específico da pintura sonora que marca o clímax da canção, na estrofe $D$, refletindo o contraste textual gerado pela mudança de estado mental do protagonista.

Como desdobramento deste estudo, torna-se quase inevitável estender o mesmo processo analítico a outras canções de Jobim, de modo a contribuir para o mapeamento do pensamento estrutural desse extraordinário compositor brasileiro.

44 Como, por exemplo, é o caso de Samba de uma nota só, composto por Jobim e Newton Mendonça em 1960. Nesta peça, a integração textual-musical atinge patamares únicos, envolvendo vários níveis e até mesmo recursos metalinguísticos. Para um estudo detalhado sobre esse caso específico, ver ALMADA (2009). 


\section{Referências}

ALMADA, Carlos (2009). Samba de uma nota só: elementos musicais a serviço da expressão poética. In: ENCONTRO ANUAL DA ANPPOM, 19., 2009, Curitiba. Anais [...]. Curitiba: UFPR, 2009.

ALMADA, Carlos. Chovendo na roseira de Tom Jobim: Uma abordagem schenkeriana. Per Musi, n. 22, p. 99-106, 2010.

ALMADA, Carlos. A Ursatz jobiniana: considerações sobre aplicações da análise schenkeriana em estudos de música popular. In: CONGRESSO LATINOAMERICANO DE FORMACIÓN ACADÉMICA EM MÚSICA POPULAR, 3., Villa Maria, 2012. Anais [...]. Villa Maria (Argentina), 2012. p. 1-10.

BUARQUE, Chico. Cancioneiro Chico Buarque: obras escolhidas. Rio de Janeiro: Jobim Music, 2008. 1 partitura. 2v.

EVERETT, Walter. The Beatles as Composers: The Genesis of Abbey Road, Side Two. In: MARVIN, Elisabeth. Concert Music, Rock, and Jazz Since 1945: Essays and Analytical Studies. Rochester: Rochester University Press, 1998. p. 172-258.

EVERETT, Walter. The Beatles as Musicians: The Quarry Men through Rubber Soul. Oxford: Oxford University Press, 2001.

FORTE, Allen. The American Popular Ballad of Golden Era, 1924-50. Princeton: Princeton University Press, 1995.

FORTE, Allen; GILBERT, Steven. Introduction to Schenkerian Analysis. New York: Norton, 1982.

GALLARDO, Cristóbal. Schenkerian analysis and popular music. Transcultural Music Review, n. 5, 2000. Disponível em: https://www.researchgate.net/publication/242626792_ Schenkerian_Analysis_and_Popular_music. Acesso em: 30 set. 2020.

GILBERT, Steven. Gershwin's Art of Counterpoint. Musical Quaterly, v. 70, n. 4, p. 423-456, 1984.

JOBIM, Tom. Songbook. Rio de Janeiro: Lumiar, 1995. 1 partitura. 3v.

JOBIM, Tom. Cancioneiro Jobim: obras escolhidas. Voz e piano. Rio de Janeiro: Jobim Music, 2006. 1 partitura. 5v. 
LARSON, Steve. Schenkerian analysis of modern jazz: Questions about method. Music Theory Spectrum, v. 20, n. 2, p. 209-241, 1998.

LARSON, Steve. Analyzing Jazz: A Schenkerian Approach. New York: Pedragon, 2009.

LERDAHL, Fred. Atonal Prolongational Structure. Contemporary Music Review, v. 4, n. 1, p. 65-87, 1989.

LERDAHL, Fred; JACKENDOFF, Ray. A Generative Theory of Tonal Music. Cambridge: The MIT Press, 1983.

LOVELL, Jeffrey. An Exploration of Melody, Harmony, and Improvisation in the Music of Stevie Wonder. Tese (PhD em Filosofia) - Universidade do Oregon, Eugene, 2012.

McFARLAND, Mark. Bill Evans and The Limits of Schenkerian Analysis. Journal of Schenkerian Studies, v. 6, p. 1-32, 2012.

McGOWAN, James. "Consonance" in Tonal Jazz: A Critical Survey of Its Semantic History. Jazz Perspectives. v. 2, n. 1, p. 69-102, 2008.

MORGAN, Robert. Dissonant Prolongation: Theoretical and Compositional Precedents. Journal of Music Theory. v. 20, n. 1, p. 49-91, 1976.

NOBILE, Drew. Counterpoint in Rock Music: Unpacking the "Melodic-Harmonic Divorce". Music Theory Spectrum, v. 37, n. 2, p. 189-203, 2015.

PELLEGRIN, Richard. On Jazz Analysis: Schenker, Salzer, and Salience. Tese (PhD em Filosofia) - Universidade de Washington, Washington D.C., 2013.

SALZER, Felix. Structural Hearing: Tonal Coherence in Music. New York: Charles Boni, 1952.

SCHOENBERG, Arnold. Harmonia. Trad. Marden Maluf. São Paulo: Editora Unesp, 2001.

STRAUS, Joseph. The Problem of Prolongation in Post-Tonal Music. Journal of Music Theory, v. 31, n. 1, p. 1-21, 1987.

STRAUS, Joseph. Introduction to Post-Tonal Theory. 3. ed. Englewood Cliffs: Prentice-Hall, 2005.

STRUNK, Steven. Linear Intervallic Patterns in Jazz Repertory. Annual Review of Jazz Studies, v. 8, p. 63-115, 1996. 
TYMOCZKO, Dmitri. A Geometry of Music: Harmony and Counterpoint in the Extended Common Practice. Oxford: Oxford University Press, 2011. 